\title{
The Influences of Actual and Perceived Familiarity on Environmental Preferences for the Design of a Proposed Urban Square
}

\author{
Tony Craig, Anna Conniff, and Carlos Galan-Diaz \\ Social, Economic and Geographical Sciences Group, The James Hutton Institute, Aberdeen AB15 8QH, UK \\ Correspondence should be addressed to Tony Craig, tony.craig@hutton.ac.uk
}

Received 8 April 2012; Revised 6 September 2012; Accepted 20 September 2012

Academic Editor: Adrian G. Aguilar

Copyright (C) 2012 Tony Craig et al. This is an open access article distributed under the Creative Commons Attribution License, which permits unrestricted use, distribution, and reproduction in any medium, provided the original work is properly cited.

\begin{abstract}
People gain actual familiarity through direct experience of environments, but environments we have never visited can still seem familiar. To date, few academic studies have investigated this phenomenon of perceived familiarity. This paper discusses the concept of perceived familiarity and environmental preference from the perspective of people who may be asked to make judgements of future urban designs as part of the planning process. A sample of local $(n=102)$ and nonlocal $(n=176)$ people were asked to rate images of two versions (existing environment and proposed redesign) of an urban square on scales of preference and perceived familiarity. Results showed that the mean ratings for the proposed design were similar for both local and non-local samples. However, we found a clearly discernible difference in the way psychological antecedents are associated with environmental preference. For nonlocals, preference for the existing design is significantly associated with preference for the proposed design, but for local people this is not the case. In addition, for non-locals perceived familiarity of the proposed design is associated with perceived familiarity of the existing environment, but for the local sample this is not the case. Implications for public participation processes in urban design, as well as limitations and future lines of research, are discussed.
\end{abstract}

"...admiration and familiarity are strangers. .."

George Sand

\section{Introduction}

Previous literature has argued that familiarity plays an important role in the formation of environmental preferences [1-3]. This paper will discuss some of the issues related to the concept of familiarity and will present empirical results from a study comparing preference responses from a sample of local and non-local people in the context of the redesign of an urban square.

In the preface to his book, Nasar [4] states that "good city appearance is not an abstract aesthetic phenomenon; it depends on the evaluations of the people who regularly experience the city". This point of view stands in contrast to those designers and urban planners who believe that "good visual form" can be pared down to a series of expert rule judgements, whose description can often at best be described as vague (see [5] for a discussion of vague terminology in planning). The idea that positive aesthetic judgement might be related to the regularity or extent of experience is something that certainly deserves more academic scrutiny. Given that it is normal practice for designers to engage in projects which are geographically dispersed, it is desirable for designers to be able to access local knowledge and views through some form of public participation [6,7].

Although there are many examples of architects and urban design practices that go to great lengths to speak to local people before suggesting a particular solution to a local design problem, it is still far from the norm. It is conceivable that a designer's professional experience may circumvent the suggested need for habitual usage in designing "good city appearance" [4]. The utility of specialist knowledge and expertise is important [8], but the fact that local design issues 
are by definition local would suggest that, where possible, design expertise should include local input.

Judgements about the quality of design vary considerably between different stakeholders. A report in 2001 by the UK Commission for Architecture and the Built Environment [9] suggested that design professionals are often concerned with building design at the expense of urban design (page 20), whereas local communities and amenity groups are usually very concerned about urban design but are often broadly conservative in outlook. The need to reconcile these various differing perspectives is at the heart of urban planning and design. Among the multiple issues within this topic, one that has received little attention to date is the question of how indicators of quality (or preference) can or should be measured, and how the different perspectives of the various stakeholders (e.g., designer/local community/developer) should be taken into account in forming these quality judgements.

This paper looks at the issue of familiarity from the perspective of people who may be asked as part of the planning process to make judgements of future urban designs. The research presented here was guided by the main research question: to what extent does a person's direct experience of an environment affect that person's preferences related to that environment?

Intuitively, familiarity is simply the result of repeated exposure to a particular stimulus or environment. Indeed, this intuitive interpretation of familiarity is the basis of the mere-exposure effect put forward by Zajonc [10], which theorises that preference for objects can be induced by repeated exposure. This kind of familiarity might be called (after Zajonc), "objective familiarity," or "actual familiarity"-a simple correlate of the number of times a person has seen a particular object or scene.

In contrast to the stimuli that were often used in early studies of environmental aesthetics, environments are most often experienced in a fairly habitual, repeated manner [11]. Regarding familiarity with environments, a further distinction can be made between "acquaintance familiarity""repeated exposure to a place, not linked to a specific aim" [12, page 256], and "functional familiarity"- "coming into contact with a place in order to reach one's goals through some activity occurring in that place" [12, page 256]. Both of these are related to the degree of exposure to a particular environment, but the second implies some form of "use." Although Mainardi Peron et al. [12] say that acquaintance familiarity is not linked to a particular aim, the logical distinction is slightly blurred since a person is rarely somewhere without a reason. It seems reasonable to say that both forms of familiarity involve repeated exposure, but only the second one (functional familiarity) involves the use of the environment for an intentional activity. For the purposes of this paper, we will use the term "actual familiarity" to denote familiarity gained through repeated exposure to a real environment (as implied by both forms of familiarity outlined by Mainardi Peron et al. [12]).

A different type of familiarity is what might be termed "perceived familiarity" - the feeling that accompanies exposure to a particular stimulus that is considered to be in some way familiar-in other words, the "glow of warmth" that Titchener (1910, cited in [10]) refers to, or the reversal of Berlyne's [13] term "novelty" [14]. This is not the same as actual familiarity for the simple reason that it is internal to the individual.

When forming a judgement regarding the familiarity of a representation of an environment (e.g., a photograph), a judgement of perceived familiarity might reasonably be expected to correlate with actual familiarity (extent of exposure). In other words, if people have been to a particular environment, they are more likely to perceive the representation of an environment to be "familiar". In addition to this, we would expect people to make comparisons between the representation (e.g., a photograph) and any other relevant environments judged by the individual to fit into a previously developed predictive schema $[3,15]$ held by that individual. In a sense, one might say that when an individual expresses a preference for a particular environmental representation, they do so within the context of their autobiographical environmental memory.

Although previous studies have indicated an important link between familiarity and preference (e.g. $[1,16])$, some studies either fail to find such a link or find the association to be relatively weak [17]. It is hard to know whether some of these findings are attributable to actual or perceived familiarity. It seems most likely that the interaction between actual and perceived familiarity is important in the formation of preferences [18]. What we have termed actual familiarity could be thought of as the potential to situate cognitive processes within actual environmental experiences. Without such experience-based potential, subjective feelings of familiarity (perceived familiarity) are likely to be more reliant on schema-based processing, where affective reactions to the physical environment result from a comparison with previous examples of a particular environmental type [15].

Many factors, including familiarity, are involved in preference formation. As we acquire additional information about an environment, we develop our understanding of that environment and revise our cognitive representations accordingly. If we experience (or even consider) a negative event in a place previously thought to be positive, our preference for that environment is likely to change. Conversely, as R. Kaplan and S. Kaplan note: "A nearby weedy field one might have complained about can suddenly look different when one hears that it might be converted into a parking structure" [2, page 114]. One could also imagine, the proposed removal of parking from an urban square might generate similar preference change. The empirical work presented later in this paper is based on such a scenario.

This paper reports on a study that allowed the relationship between actual familiarity and perceived familiarity to be studied by comparing a sample of people who had experienced being in a particular environment with people who had never been to that environment before. We were interested in the effect of having experienced a place on forming a judgement about a prospective change to the sociophysical environment. In order to answer this question, we operationalised familiarity in terms of both visual exposure (as both groups were shown a visual representation of 
the existing environment) and actual experience (as only the local group had been to the environment itself).

It is likely that people who gain actual familiarity by spending time in a particular environment would be more likely to feel a sense of satisfaction and place attachment [19, $20]$ and therefore would like it to a greater extent when compared to people who have never experienced it before. In line with this, we would expect there to be a stronger relationship between perceived familiarity and preference for people who have actual familiarity with an environment, than people who do not. Individual desire for continuity and stability associated with a particular place is likely to reflect a person's actual environmental experience, and familiarity with the place in question [21]. Furthermore, the place of residence has been found to be important in predicting both place attachment and attitudes towards the environment itself [22].

Regarding prospective preference (i.e., preference expressed for an environment that does not yet exist), there can be a large amount of visual similarity between proposed and existing designs. The reason for this is that the background context often remains constant. In the present example of an urban square, the main elements of the urban design (the shape of the square, the building facades, and a statue) were actually the same, but the function was considerably changed (from a car park to an urban square with a small increase in greenery).

For people who do not have actual familiarity with the space (i.e., non-locals), we would expect there to be a strong relationship between the initial preference for the existing design and for the new design (unless there is a very clear visual difference). On the other hand, we might expect people who are actually familiar with the environment (i.e., locals) to base their preference judgements on other, nonvisual aspects of the design as well, such as the functional aspects. In other words, for a person who lives in a particular place, the functional aspects of a design can potentially have an impact on the everyday actions available to an individual. For non-locals, there is no such potential impact, and this is likely to change the manner in which preferences are both formed and expressed. As well as the ability of places to be congruent (or otherwise) with an individual's aims, simply using a space for a defined functional purpose (e.g., parking, psychological restoration, going for a walk, etc.) in everyday life is likely to be important in terms of predicting how people will feel about the place, both now and in the future [23].

The study presented in this paper directly compares the responses of a local and non-local sample to a proposed redesign of an existing urban square. The materials presented to participants were the result of a previous study, where residents of the city were asked to choose from a number of design options. Using a three-step methodology involving a process of "enquiry by design" [24], 9 different possible design scenarios were first built up, following which a random sample of the Aberdeen population were asked to indicate which they preferred, and why (see [25] for a full description of this study). The scenario that emerged (in [25]) as the most preferred by the public in Aberdeen is the image presented as a future design proposal to participants in the remainder of this paper.

Following this, we would expect that the proposed design presented within this study to be preferred over the existing environment for the local sample.

\section{Materials and Methods}

In the current study we were interested in the extent to which experience influences environmental preference, so we decided to carry out the study on participant samples from two distinct locations-one (the local sample) where participants would have some experience of the urban square in question, and one (the non-local sample) where participants had no experience of the environment. We presented participants with photorealistic 3D computer representations of both the existing environment and the scenario that had been chosen in a previous study (in [25]) as the most preferred by the public in Aberdeen.

There were 278 participants in this study recruited from university student populations. We initially recruited 334 people, but the data from 56 participants were dropped from the analysis after applying an exclusion criterion which stated that participants in the local condition needed to have previously visited the site in Aberdeen. The fact that we used a student population for this study is useful, as it avoids the possibility of overfamiliarity, as a large number of psychology students in Aberdeen are not originally from Aberdeen (we required people to have actual familiarity, but did not wish them to be overfamiliar [2] to the extent that they may be bored). All were university students undertaking undergraduate courses in psychology ( $75 \%$ female, $25 \%$ male), and the local sample gained course credit for their participation. 94\% of participants were in the age 16-29 yrs. category. Regarding the two groups, $37 \%(N=102)$ of participants were from Aberdeen, and 63\% $(N=176)$ were from Southampton or London. To the best of our knowledge (based on the difference in time and the age of the sample), none of the participants in the current study had also been participants in Conniff et al. [25].

After completion of an informed consent form, participants were asked to provide some demographic information (sex, age, household composition), and then asked three initial questions to check participants' (actual) familiarity with the environment being studied (Golden Square, in Aberdeen). For both the existing and proposed designs/representations, participants were given an image (see Figure 1) to look at and a small amount of text to read. Images A and B were presented on separate pages of A4 paper, and participants were asked to look at image A first and then answer the questions on image $\mathrm{A}$, before doing the same for image $\mathrm{B}$. No time limits were imposed on either image viewing or questionnaire responses. The text for the "existing" scene (image A) and the "proposed" design (image B) can be seen in Table 1. Since image A was presented as the current situation, and image $\mathrm{B}$ was presented as a future design scenario, the order of presentation was fixed so that image A was always seen before image $\mathrm{B}$. 


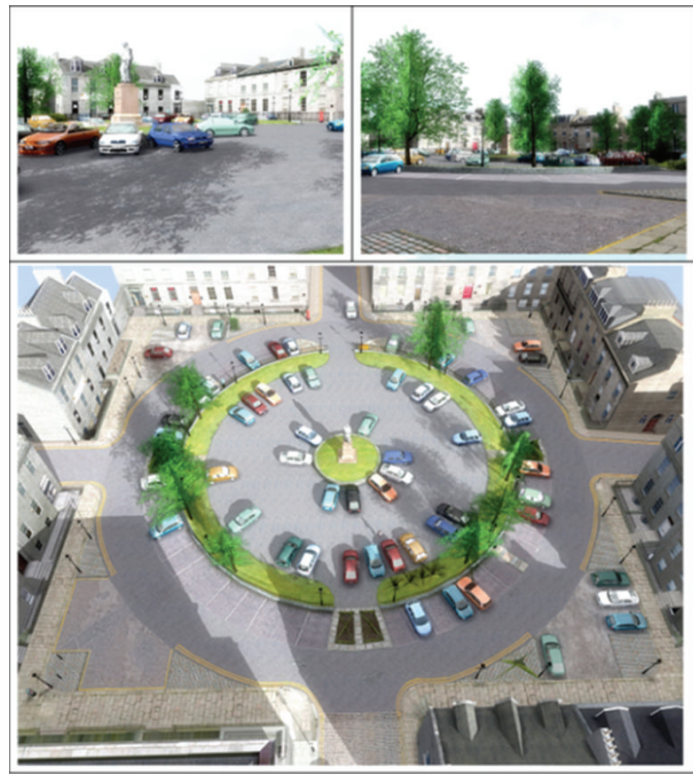

(a)

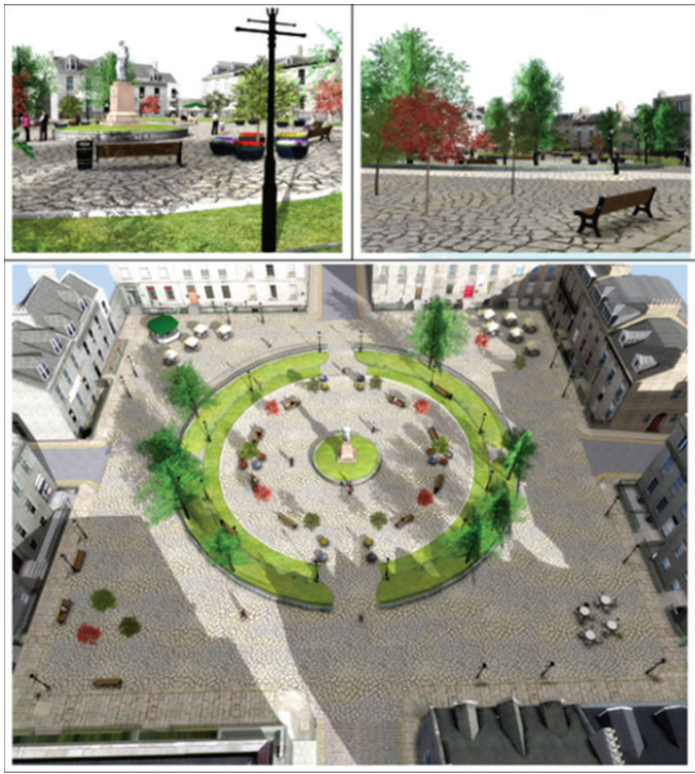

(b)

Figure 1: The two images (existing (a) and proposed (b)) presented in the study.

TABLE 1: Text accompanying images presented in the study.

\begin{tabular}{ll}
\hline & $\begin{array}{l}\text { Image A shows an urban square in the city } \\
\text { of Aberdeen called Golden Square. At } \\
\text { present (as seen in the picture) the square is } \\
\text { mainly used as a car park, usefully located } \\
\text { within the city centre. }\end{array}$ \\
\hline Image B (proposed) & $\begin{array}{l}\text { In this design scenario, all the car-parking } \\
\text { will be removed from the square, the centre } \\
\text { will be made into a small urban park, and } \\
\text { cafe seating will be added in the corners. }\end{array}$ \\
\hline
\end{tabular}

After examining the stimulus materials, participants were then asked to complete the following six 9-point likerttype semantic differential scales (based on [3]): "beautifulugly", "pleasant-unpleasant", "like-dislike", "simple-complex", "plain-ornate," and "familiar-unfamiliar". Participants were also asked two open ended questions about what they liked and disliked about the environment depicted. Scale scores for beauty, pleasure, liking, and familiarity were reversed prior to further analyses.

\section{Results}

Visual screening of the data was carried out prior to analyses, and it was noticed that the scores on the "perceived familiarity" judgement seemed to include a systematic response tendency for the non-local group. What we found was that people in the non-local group were significantly more likely to use the extreme end response point of the "unfamiliar" scale. We therefore removed all data from participants who exhibited this response tendency for either image. This process involved removing 50 responses from the total sample, leaving a remaining sample of 228 (95 local and 133 nonlocal). This process resulted in the sample distribution more closely approximating a normal distribution. Figure 2 shows the effect of removing these responses on the distribution of scores.

Scales were constructed following Imamoglu [3], to allow comparability of results. The variables preference (including the three scales after reverse-coding: "beautiful-ugly", "pleasant-unpleasant", "like-dislike") and ornateness-complexity (including the scales: "simple-complex" and "plainornate") were computed, and the reliability of each scale was checked for responses to both images. The preference scale was found to be high in terms of internal consistency (Cronbach $\alpha=0.90$ for image A responses; Cronbach $\alpha=$ 0.93 for image $B$ responses). The alpha coefficients for the ornateness-complexity scales were, however, below the threshold of 0.70 (Cronbach $\alpha=0.56$ for image A responses; Cronbach $\alpha=0.69$ for image $\mathrm{B}$ responses), which we set as the minimum level. As a result, it was decided that only the preference scale should be used as a reliable scale in the study. Correlations between perceived familiarity and preference for the local and non-local sample are shown in Figure 3. These correlations show that the association between constructs does seem to vary depending on which sample participants are from. For example, participants in the non-local sample show a significant correlation between ratings of image $A$ and ratings of image $B$, whereas participants in the local sample do not. This may suggest that the psychological mechanisms involved in the formation of preference are different depending on whether or not the environment has been experienced in real life.

The relationship between locality and perceived familiarity was checked by comparing the two groups' responses on the perceived familiarity judgement of the first image 


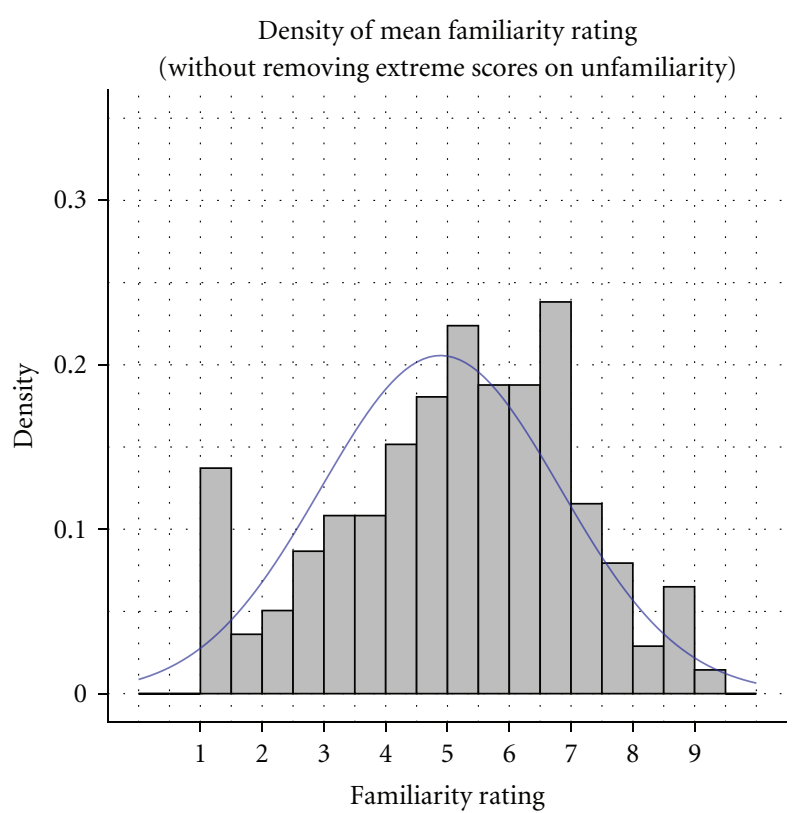

(a)

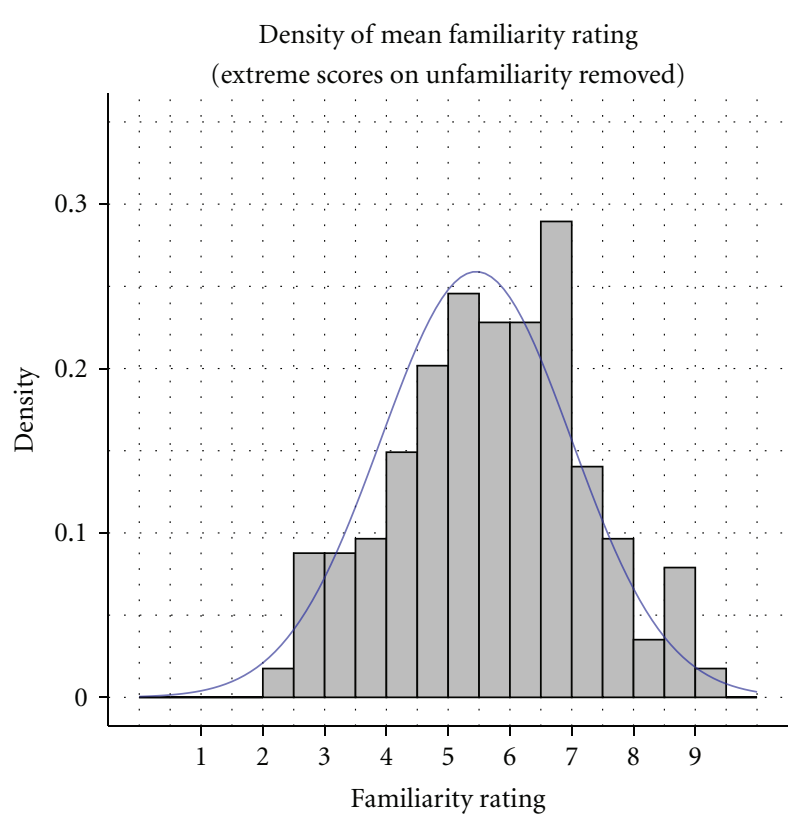

(b)

FIGURE 2: Density histograms before and after removing systematic response tendency for extremely low levels of familiarity.

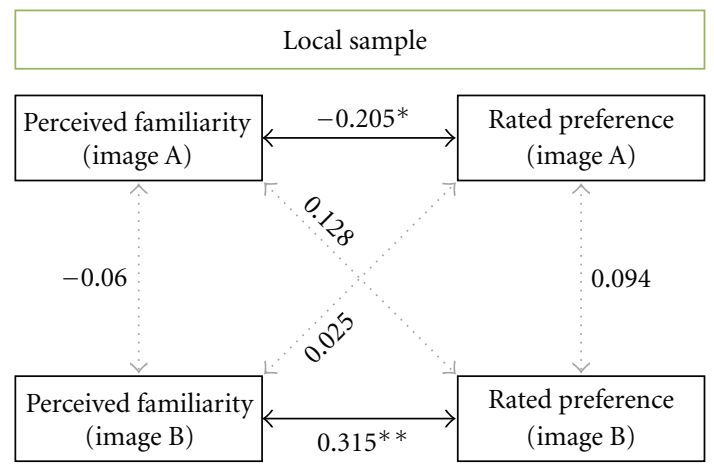

(a)

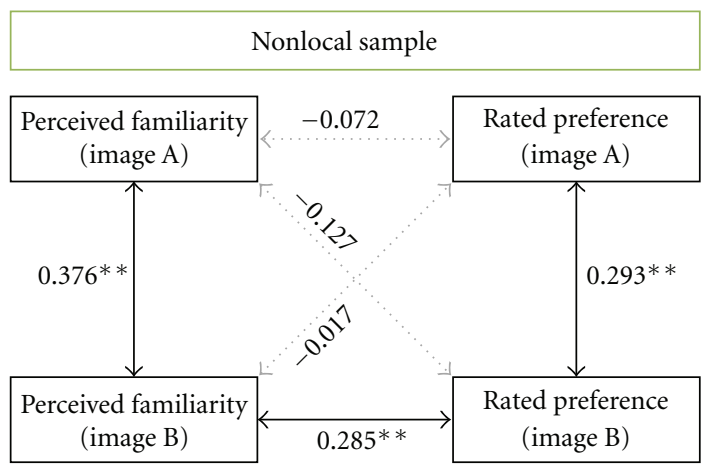

(b)

FIgURE 3: Pearson correlation coefficients between perceived familiarity and rated preference scores for images A and B (separate diagrams for local and non-local samples). ${ }^{*}$ Correlation significant at the $P<0.01$ level; ${ }^{*}$ Correlation significant at the $P<0.05$ level.

(image A). The effect sizes for the $t$-test are reported using Cohen's $d$, which is an estimate of the standardized difference between two groups. Participants from the local $(M=6.68$, $S D=1.68)$ and non-local $(M=4.57, S D=1.81)$ conditions were significantly different in terms of perceived familiarity judgements, $t(226)=8.96, P<0.001$, and $d=1.19$. As such the experimental manipulation was considered to be effective, and in the predicted direction. We found that perceived familiarity judgements for the proposed design (image B) were not significantly different between the local $(M=5.69$, $S D=2.03)$ and non-local $(M=5.29, S D=1.81)$ groups, $t(226)=1.60, P=0.11$, and $d=0.21$. These findings are illustrated in the left hand graph in Figure 4.

We also checked for differences in rated preference and found that there was no significant difference in the mean scores based on locality for either image. In terms of image
A, participants from the local $(M=5.92, S D=1.37)$ and non-local $(M=5.99, S D=1.45)$ conditions were not significantly different in terms of rated preference scores, $t(226)=$ $-0.327, P=0.744, d=-0.04$. This shows that the mean baseline preference for the existing design was essentially the same for both the local and the non-local sample. We expected that when it came to judging image $B$, there would be a significant difference in preference (with local people expressing a higher preference for the proposed design) because of the influence of experience, but we found no significant differences in the ratings of local $(M=7.22$, $S D=1.60)$ and non-local $(M=7.05, S D=1.46)$ groups, $t(226)=0.876, P=0.382$, and $d=0.12$. These findings are illustrated in the right hand graph in Figure 4.

We examined the relationship between perceived familiarity and locality (left hand graph in Figure 4) further by 


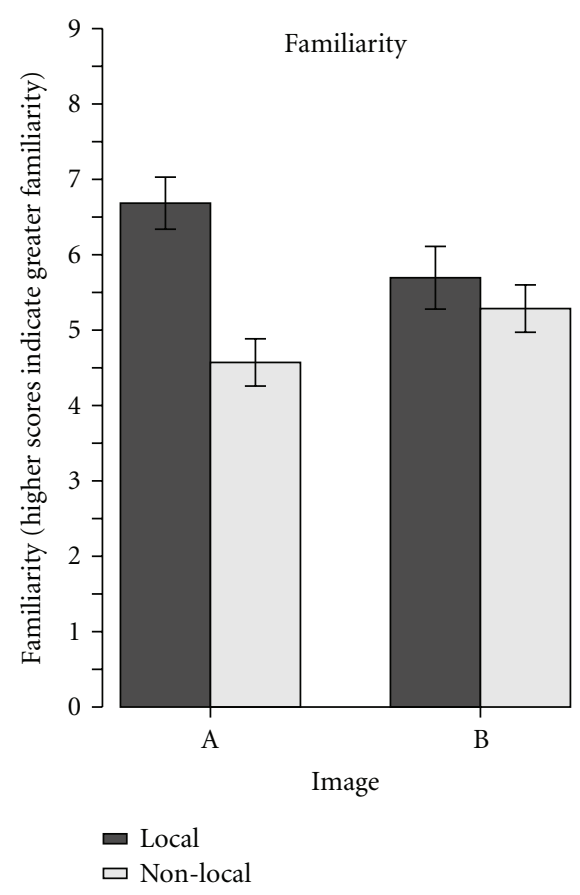

(a)

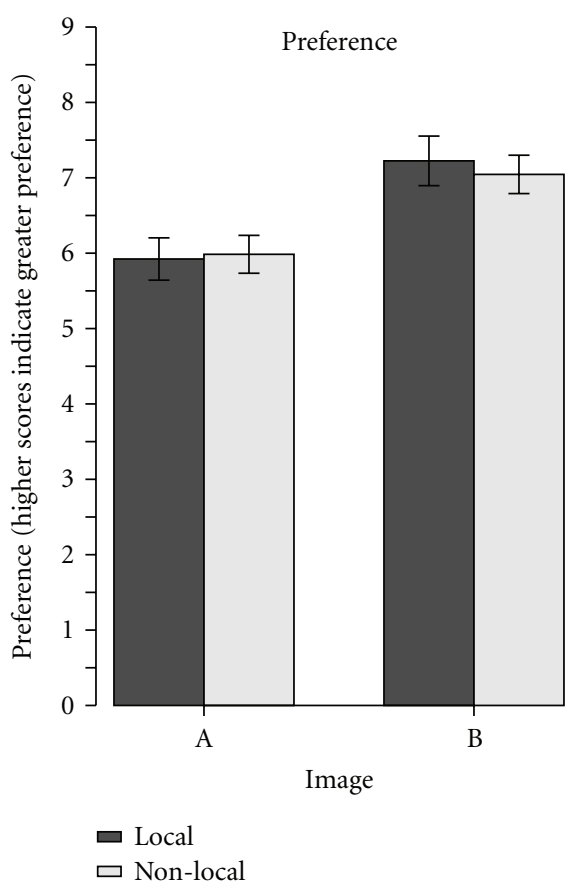

(b)

FIGURE 4: Mean ratings of familiarity and liking for local and non-local participants for both images (error bars: $+/-2$ SE).

conducting a mixed ANOVA with locality as a betweensubjects factor (a between-subjects factor is a variable indicating that people come from different groups-in this case the two levels of this factor are local and non-local) and perceived familiarity (of image A or B) as a within-subjects factor (a within-subjects factor is a variable that is measured at different levels within a study. In this case, the withinsubjects factor is "image", meaning that the questionnaire responses are asked for twice- once for image $\mathrm{A}$ and once for image B). The effect sizes for the ANOVA are reported using the partial Eta-squared $\left(\eta^{2}\right)$ estimate, which is an estimate of the explained variance, analogous to $R^{2}$ in multiple linear regression. The results show that the main effect of betweensubjects factor (locality) was significant $(F(1,226)=44.184$, $\left.P=0.000, \eta^{2}=0.164\right)$, and the main effect of image was not significant $\left.F(1,226)=0.771, P=0.381, \eta^{2}=0.003\right)$. In addition, the ANOVA results show that the interaction between image and location was significant $(F(1,226)=$ 29.554, $\left.P=0.003, \eta^{2}=0.116\right)$. This significant interaction suggests that local participants tend to express reduced levels of perceived familiarity for the proposed design compared to the existing design, whereas non-local participants do not.

We examined the relationship between rated preference and locality (right hand graph in Figure 4) by conducting a similar mixed ANOVA with locality as a between-subjects factor and rated preference (of image A or B) as a within subjects factor. The results show the opposite pattern to that found for perceived familiarity. The main effect of location was not significant $(F(1,226)=0.146, P=0.703$, $\left.\eta^{2}=0.001\right)$, and the main effect of image was significant $\left(F(1,226)=90.167, P<0.001, \eta^{2}=0.285\right)$. The interaction between image and location was not found to be significant $\left.F(1,226)=0.943, P=0.332, \eta^{2}=0.004\right)$. These findings suggest that participants tend to prefer image $B$, regardless of whether or not they are local. The pattern of correlations shown in Figure 3, as noted earlier, suggests that the mechanisms underlying the formation of these preferences may be very different.

The mechanisms underlying the formation of preferences were explored through the responses to the two openended questions addressing what participants liked and disliked about the scenes presented in the images. The responses were collated and content-analysed. Word frequencies were calculated using Nvivo (version 9), and pertinent findings are described below.

Taking both local and non-local responses together, what participants like best about image A can be summarised as greenery (144 counts of the terms grass, trees, green and greenery) and layout (119 counts of the terms shape, circular, layout, symmetry, symmetrical, and design). It can be conjectured that the prevalence of the terms relating to layout may be due to the aerial nature of the main image presented, where the arrangement of the square can be best understood. This, of course, is not the view that people would encounter on a real visit to the square, and it would be interesting to compare results where no birds-eye view is presented.

With respect to image $\mathrm{B}$, the most frequent comments from local and non-local participants relate to the appearance and "Feel" of the square (77 counts of the terms relaxing, nice, peaceful, pretty, pleasant, and attractive), the Greenery (66 counts of the terms greenery, green, plants, and trees), and Seating (63 counts of the terms benches, seating, and sit). 
In contrast to image $\mathrm{A}$, there are no comments using the Layout terms, although there are 27 mentions of space and 43 of area. One way to interpret this is that because participants are comparing image $\mathrm{B}$ to image $\mathrm{A}$, they simply do not refer to the immutable components of the square.

When the likes of local and non-local participants are compared, for image A we see a marked difference in the frequency of cars and parking-for the local sample this is greater $(7 \%)$ than for the non-local sample (5\%). Nonlocal people like the circularity of the square more than local people (5\% compared to $3 \%$ ) and the symmetry/symmetrical aspect (4\% compared to $2 \%)$. The non-local group also likes the greenery aspects presented in image A (trees, grass, greenery) to a greater extent than the local group (15\% compared to $13 \%$ ). For the dislikes of the local and non-local samples with respect to image A, there is a little difference. Cars and parking are the most frequently mentioned dislike for both the local group (18\%) and the non-local sample $(19 \%)$.

With respect to liking for image $B$, the non-local sample cite the benches (benches, seating, sit) (7\%) more than the local sample (4\%) and also mention the Greenery (greenery, trees, green, plants) $(7 \%)$ more than the local sample (5\%). The non-local sample mention they dislike nothing (4\%) more than the local sample (2\%). The most frequently disliked element for the local sample is the lack of parking spaces (6\%). Interestingly, the non-local sample also cite the lack of parking spaces as a relatively common dislike (5\%).

One further observation is that some of the results for the local respondents do not necessarily read as comments regarding a place they know. It is as if some have taken the instruction "What do you like about this scene?" literally and view the image objectively, as a picture rather than a representation of somewhere they are acquainted with, for example, "the simple circular design with the cars scattered around looks almost toy-like", "clear geometry and shadows created", "the bright green grass and colourful cars". This may be due to the nature of the image itself being computer-generated and looking slightly different to how Golden Square appears in real life ("how CAD makes it seem nicer than it actually is"). Clearly we would expect this to only have an effect for the local respondent group.

\section{Discussions and Conclusions}

This paper has shown that actual experience with an environment affects the way in which people respond to proposals to change that environment. Whilst there were no significant differences between the preference ratings of locals and non-locals, there was a clearly discernible difference in the way psychological antecedents are associated with environmental preference.

We found that non-local participants in this study seemed to use different information to local participants when forming environmental preference. The results show that in the case of non-local people, the perception of familiarity of the proposed design is strongly related to the perception of familiarity of the existing environment (see Figure 3).
However, this relationship was not found to be significant for the local sample. This suggests that there may be a spillover of perceived familiarity for non-local people based on the initial visual experience of being shown the existing environment.

In a similar manner, there was a significant relationship between preference for the existing environment and preference for the proposed design in the non-local sample, but not for the local sample. In other words, if non-local participants liked image A, they were more likely to like image B. Again, this suggests a kind of spill-over effect, whereby environmental preference judgements made at the first visual experience are carried over to the judgement of the proposed design. We suspect that this relationship does not occur for the local sample because perceived familiarity is a psychologically different construct when a person has no actual memory of a place. Local people, who are familiar with an environment, base their judgements on a wider range of factors (e.g., environmental function, local history, culture, and climate) compared to non-local people, who are necessarily limited to the design information with which they are presented. The fact that in any given project, the majority of urban designs share key contextual features makes the existing and proposed environments seem less different for non-local people.

It seems likely that this difference is due to the fact that nonmeasured constructs (e.g., place identity, attachment, etc.) are not considered here. Indeed, if they were (which would require further research), one would expect that such predictors would be significant for the local group, but not for the non-local group.

These findings have implications for public participation processes, as they may suggest that knowing the level of people's experience with a place might be a useful measure if one is trying to predict preference.

In the context of public participation in design, it is important to acknowledge that in most cases, designs either add something new to an undeveloped environment, or attempt to satisfy functional requirements (e.g., adding buildings to existing urban settings) at the same time as improving the visual aesthetic within that setting. This connotation of "improvement" is important because many existing environments that people are familiar with may not be held in particularly high regard-especially degraded environments low in landscape value. It would be interesting to look at the relationship between negative reactions and familiarity (i.e. familiar but disliked environments), to explore how the features of the existing environment may modify the relationship between actual familiarity and preference.

It would also be worthwhile exploring whether simply gaining knowledge about an environment may be able to supplement actual familiarity in some way. In a study investigating the effect of knowledge of how landscapes (the Lake District and the Trossachs) used to look and be perceived on preference for future landscape change, Hanley et al. [26] found that knowledge of how landscapes have changed in the past can influence people's opinions about future change and make them more favourable towards change. It would be interesting in a future study to investigate 
the effect of providing more detailed information about the current use of an area to unfamiliar participants. This would allow a more detailed investigation of the effect of local knowledge on preference formation.

Our analysis of the open-ended comments highlighted the similarities and differences between the local and nonlocal participants, particularly with respect to the proposed new design. As discussed in the introduction, a distinction can be made between "acquaintance familiarity" and 'functional familiarity' [12]. For image A, local participants expressed more liking of the functional (parking) element of the square compared to non-local participants. Interestingly however, with respect to image $B$, although the local sample cited lack of parking spaces as a more frequent dislike than the non-local sample, the fact that the non-local sample mentioned it at all is arguably indicative of a near-universal desire for specific functional uses of urban spaces-in this case car parking.

Our analysis of the open-ended comments in this study highlighted the issue of the viewpoint of Golden Square that was presented to respondents, that is, an aerial view. Whilst this enabled a clear understanding of the layout of the square, it is not a view that would be encountered by visitors to the square, whether familiar or not. The viewpoint is only one of many issues that can be taken with visual representations of current and future environments, and this could be the subject of future research.

Future studies concerned with the relationship between familiarity and preference may benefit from the development of a multiple-item measure of perceived familiarity. This study used a single-item bipolar scale, but we would recommend that future research should explore the construction of reliable familiarity scales. The current study was also based on a relatively low sample size, and future research would benefit from the inclusion of a larger number of participants. Additionally, it has been suggested that considering the impact of mood at the time of evaluation can affect preference [27], and future research may benefit from considering this. This could be done by including measures such as the Positive Affect and Negative Affect Schedule [28] prior to the evaluation task.

Finally, we would recommend that other case studies involving the introduction of nonfamiliar man-made structures into existing environments look at these issues of perceived and actual familiarity in more depth. One example, where this would be particularly interesting, is that of microrenewable energy installations (e.g., solar-PV, or microwind turbines) within urban environments, or large offshore wind farms visible from coastal urban settings. The familiarisation process related to wind energy developments has often been documented as a positive change in terms of aesthetic and functional adaptation on a local level. Essentially, while expressed fear of uncertainty related to change is not unusual, many people become more accepting of wind energy installations after they have been constructed, and therefore experienced [29]. That said, the polarisation of views related to landscape and urban planning is very often based on aesthetic considerations, so, given our findings, it would be interesting to know what degree of familiarisation (either in vitro-e.g., by watching a film, or in vivo-e.g., via a site visit) would be required for people to be able to approximate their reactions to a real development.

Only with actual familiarity and experience can views be truly thought to be representative. Many authors have documented the importance of place attachment [30] and place identity [31] on the formation and expression of environmental preferences and evaluative judgements [32-34]. However, very little research has systematically compared the responses of local and non-local groups to design proposals. This paper has shown the value in doing such comparisons, and has demonstrated that even when local and non-local samples express the same positive environmental preference, their reasons for doing so may differ considerably, with nonlocal people placing more weight on what might be termed before-after visual comparisons, and local people placing more weight on functional attributes of the design, such as parking. We hope that future research will be able to grow this evidence base, which we believe is of both theoretical and practical value.

\section{Acknowledgments}

The work was initially supported by a grant from the Carnegie Trust, which enabled the research to be carried out in places where familiarity with Aberdeen was low. We also acknowledge funding from the Scottish Government Rural and Environment Science and Analytical Services Division (RESAS). The authors would like to thank Stephen Scott and Richard Laing for their work in a separate research project in which the computer images were generated. Thanks also to Anke Fisher, Jill Dunglinson, and Simon Heslop for their helpful comments on an earlier draft of this publication. The authors are also grateful for the useful suggestions made by the anonymous reviewers.

\section{References}

[1] D. M. Pedersen, "Relationship between environmental familiarity and environmental preference," Perceptual and Motor Skills, vol. 47, pp. 739-743, 1978.

[2] R. Kaplan and S. Kaplan, The Experience of Nature: A Psychological Perspective, Cambridge University Press, Cambridge, UK, 1989.

[3] Ç. Imamoglu, "Complexity, liking and familiarity: architecture and non-architecture Turkish students' assessments of traditional and modern house facades," Journal of Environmental Psychology, vol. 20, no. 1, pp. 5-16, 2000.

[4] J. L. Nasar, The Evaluative Image of the City, Sage, Thousand Oaks, Calif, USA, 1998.

[5] A. E. Stamps III, Psychology and the Aesthetics of the Built Environment, Kluwer Academic, Boston, Mass, USA, 2000.

[6] H. Sanoff, Community Participation Methods in Design and Planning, John Wiley \& Sons, New York, NY, USA, 2000.

[7] J. L. Nasar, "Urban design aesthetics — the evaluative qualities of building exteriors," Environment and Behaviour, vol. 26, pp. 377-401, 1994.

[8] F. H. Sancar, "Paradigms of postmodernity and implications for planning and design review processes," Environment and Behavior, vol. 26, pp. 312-337, 1994. 
[9] CABE, The Value of Urban Design, Commission for Architecture and the Built Environment, London, UK, 2001.

[10] R. B. Zajonc, "Feeling and thinking: preferences need no inferences," American Psychologist, vol. 35, no. 2, pp. 151-175, 1980.

[11] J. F. Wohlwill, "Environmental aesthetics: the environment as a source of affect," in Human Behaviour and EnvironmentAdvances in Theory and Research, I. Altman and J. F. Wohlwill, Eds., vol. 1, pp. 37-86, Plenum Press, New York, NY, USA, 1976.

[12] E. Mainardi Peron, M. R. Baroni, R. Job, and P. Salmaso, "Effects of familiarity in recalling interiors and external places," Journal of Environmental Psychology, vol. 10, no. 3, pp. 255-271, 1990.

[13] D. E. Berlyne, Studies in the New Experimental Aesthetics: Steps Toward an Objective Psychology of Aesthetic Appreciation, Wiley, New York, NY, USA, 1974.

[14] J. Russell and J. Snodgrass, "Emotion and the environment," in Handbook of Environmental Psychology, D. Stokols and I. Altman, Eds., pp. 245-281, Wiley Interscience, New York, NY, USA, 1987.

[15] A. T. Purcell, "Environmental perception and affect: a schema discrepancy model," Environment and Behavior, vol. 18, pp. 3 30, 1986.

[16] A. T. Purcell, E. Peron, and R. Berto, "Why do preferences differ between scene types?" Environment and Behavior, vol. 33, no. 1, pp. 93-106, 2001.

[17] J. D. Wellman and G. J. Buhyoff, "Effects of regional familiarity on landscape preferences," Journal of Environmental Management, vol. 11, no. 2, pp. 105-110, 1980.

[18] P. Anand and M. Holbrook, "Reinterpretation of mere exposure or exposure of mere reinterpretation?" Journal of Consumer Research, vol. 17, pp. 242-244, 1990.

[19] M. Bonaiuto, A. Aiello, M. Perugini, M. Bonnes, and A. P. Ercolani, "Multidimensional perception of residential environment quality and neighborhood attachment in the urban environment," Journal of Environmental Psychology, vol. 19, no. 4, pp. 331-352, 1999.

[20] S. Low and I. Altman, "Place attachment-a conceptual enquiry," in Place Attachment, I. Altman and S. Low, Eds., pp. 1-12, Plenum Press, New York, NY, USA, 1992.

[21] K. L. Henwood and N. F. Pidgeon, "Talk about woods and trees: threat of urbanization, stability, and biodiversity," Journal of Environmental Psychology, vol. 21, no. 2, pp. 125-147, 2001.

[22] M. Bonaiuto, G. Carrus, H. Martorella, and M. Bonnes, "Local identity processes and environmental attitudes in land use changes: the case of natural protected areas," Journal of Economic Psychology, vol. 23, no. 5, pp. 631-653, 2002.

[23] M. Bonnes, P. Passafaro, and G. Carrus, "The ambivalence of attitudes toward urban green areas: between proenvironmental worldviews and daily residential experience," Environment and Behavior, vol. 43, no. 2, pp. 207-232, 2011.

[24] J. Zeisel, Inquiry by Design. Tools for Environmental-Behaviour Research, Brooks/Cole, Monterey, Calif, USA, 1981.

[25] A. Conniff, T. Craig, R. Laing, S. Scott, and C. R. GalánDíaz, "Informing the practice of planning: researching future environments using desktop computers," in Environmental Psychology: From Research to 'Real World' Applications, E. Edgerton and O. Romice, Eds., pp. 91-108, Cambridge Scholars Publishing, Newcastle, UK, 2007.

[26] N. Hanley, R. Ready, S. Colombo, F. Watson, M. Stewart, and E. A. Bergmann, "The impacts of knowledge of the past on preferences for future landscape change," Journal of Environmental Management, vol. 90, no. 3, pp. 1404-1412, 2009.

[27] L. Mealey and P. Theis, "The relationship between mood and preferences among natural landscapes: an evolutionary perspective," Ethology and Sociobiology, vol. 16, no. 3, pp. 247256, 1995.

[28] D. Watson, L. A. Clark, and A. Tellegen, "Development and validation of brief measures of positive and negative affect: the PANAS scales," Journal of Personality and Social Psychology, vol. 54, no. 6, pp. 1063-1070, 1988.

[29] C. R. Warren, C. Lumsden, S. O'Dowd, and R. V. Birnie, "'Green on green': public perceptions of wind power in Scotland and Ireland," Journal of Environmental Planning and Management, vol. 48, no. 6, pp. 853-875, 2005.

[30] S. Low, "Symbolic ties that bind: place attachment in the plaza," in Place Attachment, I. Altman and S. Low, Eds., pp. 165-185, Plenum Press, New York, NY, USA, 1992.

[31] H. M. Proshansky, A. K. Fabian, and R. Kaminoff, "Placeidentity: physical world socialization of the self," Journal of Environmental Psychology, vol. 3, no. 1, pp. 57-83, 1983.

[32] P. Devine-Wright and Y. Howes, "Disruption to place attachment and the protection of restorative environments: a wind energy case study," Journal of Environmental Psychology, vol. 30, no. 3, pp. 271-280, 2010.

[33] B. Hernández, M. Carmen Hidalgo, M. E. Salazar-Laplace, and S. Hess, "Place attachment and place identity in natives and non-natives," Journal of Environmental Psychology, vol. 27, no. 4, pp. 310-319, 2007.

[34] S. Tapsuwan, Z. Leviston, and D. Tucker, "Community values and attitudes towards land use on the Gnangara Groundwater System: a sense of place study in Perth, Western Australia," Landscape and Urban Planning, vol. 100, no. 1-2, pp. 24-34, 2011. 


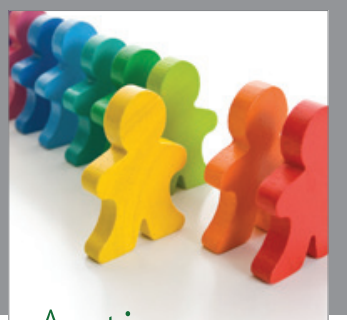

Autism

Research and Treatment
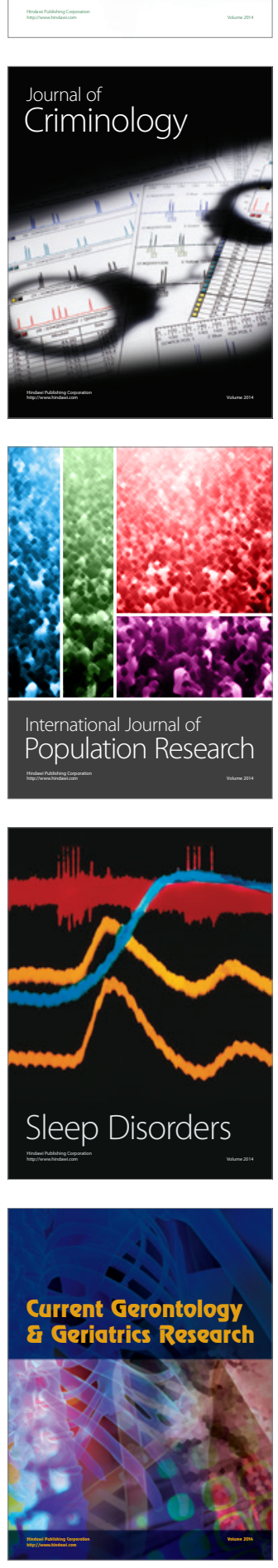
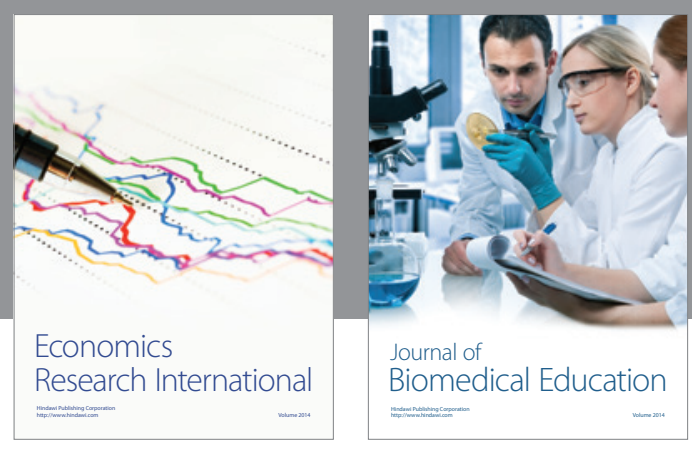

Journal of

Biomedical Education

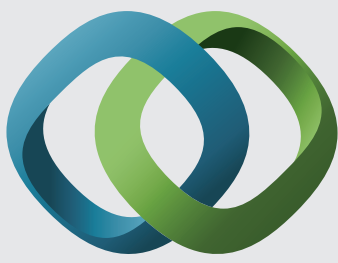

\section{Hindawi}

Submit your manuscripts at

http://www.hindawi.com
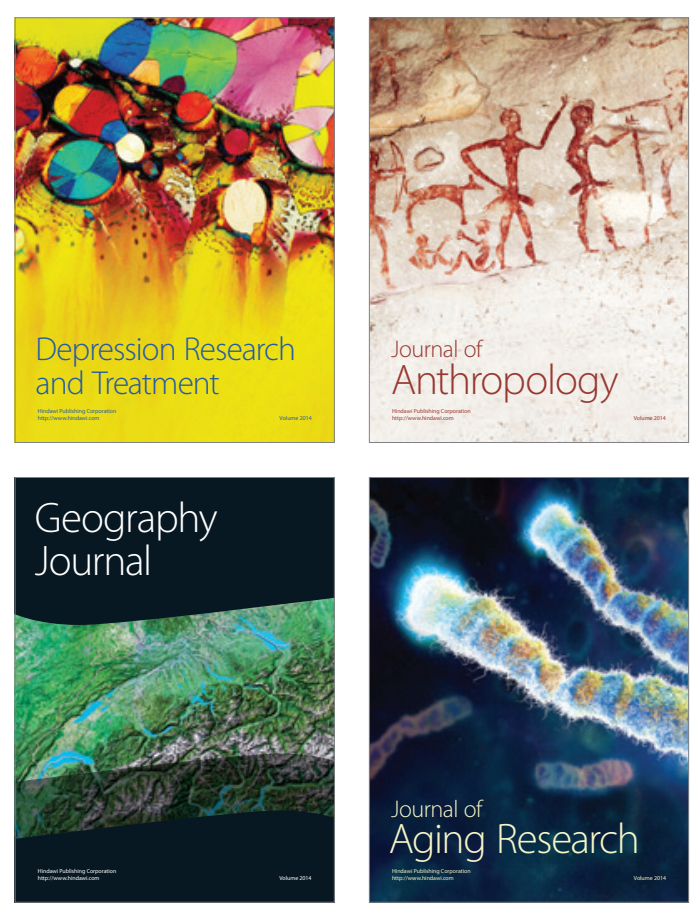

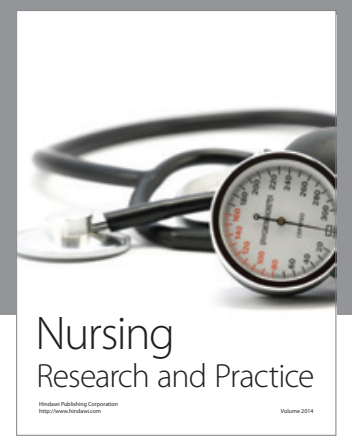

Nursing

Research and Practice

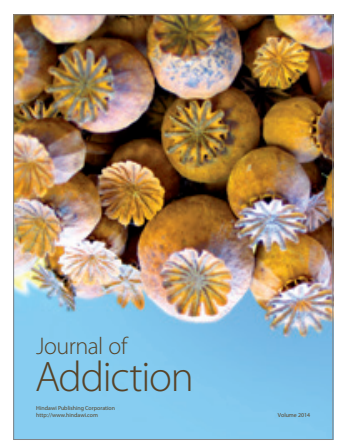

Child Development

Research

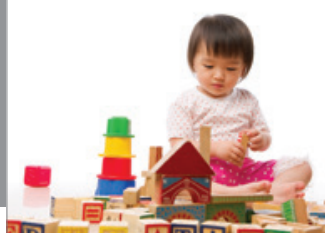

迥
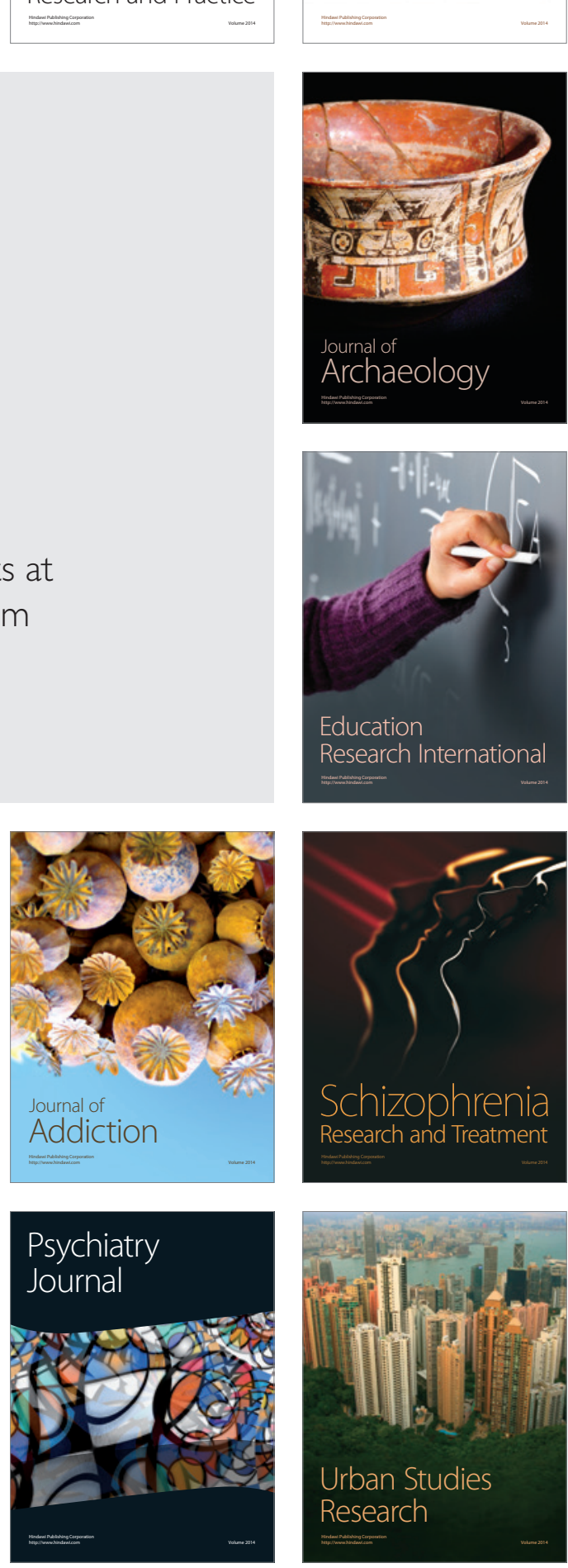